\title{
Using automated supplementation systems to meet growth targets for grazing sheep
}

\author{
M. K. Bowen $\mathrm{A}, \mathrm{C}, \mathrm{D}$, P. M. Pepper ${ }^{\mathrm{B}}$, J. L. Winkleman ${ }^{\mathrm{A}}$, R. C. McPhie $\mathrm{A}$ \\ and M. R. Winter ${ }^{\mathrm{A}}$ \\ ADepartment of Primary Industries and Fisheries, PO Box 519, Longreach, Qld 4730, Australia. \\ BDepartment of Primary Industries and Fisheries, Locked Mail Bag 4, Moorooka, Qld 4105, Australia. \\ CPresent address: Department of Primary Industries and Fisheries, PO Box 6014, \\ Rockhampton Mail Centre, Qld 4702, Australia. \\ DCorresponding author. Email: maree.bowen@dpi.qld.gov.au
}

\begin{abstract}
Remote drafting technology now available for sheep allows targeted supplementation of individuals within a grazing flock. This paper reports results of three experiments. Experiment 1 examined the weight change of Merino wethers allowed access to either lupin grain or whole cottonseed 0, 1, 2 or 7 days/week for 6 weeks. Experiment 2 examined the weight change of Merino wethers allowed access to either lupins or a sorghum + cottonseed meal (CSM) supplement 0, 2, 4 or 7 days/week for 8 weeks. Experiment 3 investigated the relationship between five allocations of trough space at the supplement self-feeders $(5-50 \mathrm{~cm} / \mathrm{sheep})$ and the weight change of Merino wethers allowed access to lupins 1 day/week for 8 weeks. In all experiments, the Merino wethers had free access as a single group to drinking water and low quality hay in a large group pen and were allowed access to supplement once per day on their scheduled days of access. No water was available in the areas containing supplement, but one-way flow gates allowed animals to return to the group pen in their own time.

There was a linear response in growth rate to increased frequency of access to lupins in Experiments 1 and 2, with each additional day of access increasing liveweight gain by 26 and $21 \mathrm{~g} /$ day, respectively. Similarly, the response to the sorghum + CSM supplement was linear, although significantly lower $(P<0.05)$, at $12 \mathrm{~g} / \mathrm{day}$. Providing access to whole cottonseed resulted in no significant change in growth rate compared with the control animals. In Experiment 3 , decreasing trough space from 50 to $5 \mathrm{~cm} /$ sheep had no effect on sheep liveweight change.

It was concluded that the relationships developed here, for growth response to increased frequency of access to lupins or a sorghum + CSM supplement, could be used to indicate the most appropriate frequency of access to supplement, through a remote drafting unit, to achieve sheep weight change targets. Also, that a trough space of $5 \mathrm{~cm} / \mathrm{sheep}$ appears adequate in this supplementation system.
\end{abstract}

Additional keywords: precision nutrition, rangeland.

\section{Introduction}

New remote drafting technology will enable individual management of sheep grazing together as a flock (Rowe and Masters 2005; Rowe and Atkins 2006). This technology allows sheep tagged with radio frequency identification (RFID) to be automatically drafted as they enter or exit water points. An example of the application of this technology is the targeted supplementation of breeding ewes so that only those animals that require supplement are fed (Rowe 2004; Jordan et al. 2006). An advantage of this approach is the potential to make supplementation under grazing conditions more economical and efficient.

One option for using the remote drafting system for targeted feeding involves giving selected sheep free access to supplement in a fenced area without access to water. The amount of feed eaten is therefore limited in part by the need to drink. After returning to the paddock via one-way flow gates, the animal cannot access the supplement again until it is drafted into the feed area according to a pre-set schedule of access. The frequency of access to the supplement can be varied from access each time the animal passes through the drafter (even if this is several times per day) to access once per week or even once per fortnight. There is therefore opportunity to determine which sheep in the flock obtain access to supplementary feed and to manipulate the level of feeding on an individual basis.

An understanding of the relationship between frequency of supplement feeding and rate of weight change is needed so that sheep can be managed to achieve specific growth targets. Numerous studies have examined the consequences of feeding a restricted amount of supplement at various time intervals, with many finding that less frequent feeding of supplements was not detrimental to animal performance (e.g. Hawthorne and Stacey 1984; Egan et al. 1987; Bohnert et al. 2002) or produced only mildly negative effects (Beaty et al. 1994; Farmer et al. 2001). However, work by Godfrey et al. (1993) showed linear, but 
relatively minor, decreases in animal performance with decreased frequency of feeding of both legume and cereal grains, although the feeding intervals used (up to 14 days) were relatively extreme compared with the more conventional range of feeding every 3-4 days.

Although the issue of optimal frequency of supplement feeding has been examined previously, the principles have not been examined in a context applicable to the remote drafting technology where ruminants graze as a group with selected individuals receiving free access to supplement in exclusion zones after passing through a drafting device. In this situation, the frequency of access to supplement may have an effect on the amount of supplement consumed.

Lupin grain is a safe and nutritious supplement used widely for sheep in temperate environments in Australia and, as such, would seem an obvious choice for use in a supplementation system based on the remote drafting technology. However, in tropical and subtropical areas of Australia, sorghum grain and protein supplements based on cottonseed are normally readily available and at a more attractive price than lupins. Previous experiments with lambs (Bowen et al. 2007b) and cast-for-age ewes (Bowen et al. 2007a) demonstrated that concentrates based on sorghum grain and cottonseed products can provide suitable diets for feedlot finishing sheep. However, acidosis is a concern when providing cereal grains ad libitum to sheep and particularly when the grain is offered infrequently.

Including salt in supplements for ruminants has been effective in limiting supplement intake (Riggs et al. 1953; Beeson et al. 1957; Easton et al. 1998; Simeone et al. 2003; Schauer et al. 2004). However, the level of salt inclusion at which supplement intake has been restricted has varied from 5\% (Beeson et al. 1957) to 44\% (Easton et al. 1998) and would be influenced by factors such as the palatability of the supplement and the salt content of the diet and drinking water. Preliminary testing before commencing our experiment indicated that $7 \%$ salt inclusion in a sorghum and cottonseed meal supplement appeared optimal for achieving the dual objectives of restricting supplement intake, whilst minimising excessive sorting and selection against the salt component.

Dominance hierarchies and competition between animals can contribute to intake variation when a finite feeding area or trough space is available. Bowman and Sowell (1997) concluded that there seemed to be an optimum level of feeding competition that reduces intake variation and improves the proportion of animals consuming adequate amounts of supplement, but that this optimum varies with the feeding situation.

Industry recommendations for trough space allocation under feedlotting conditions are $10 \mathrm{~cm}$ of trough space/sheep for selffeeders and $15 \mathrm{~cm}$ of trough space/sheep when open troughs are used (Bell et al. 2002; Davis 2003). However, these recommendations may not be relevant to the remote drafting supplementation system where sheep are provided with infrequent access to supplement as they exit water points in a grazing system. Furthermore, a recent review by Jolly and Wallace (2006) concluded that existing guidelines for feed access space for sheep vary significantly and can be considered unreliable. In the application of the remote drafting technology, it will be important to determine the effect of trough space allocation per sheep at the supplement self-feeder on sheep weight change, so that sheep can be managed to achieve specific growth targets.

The objectives of this research were to compare the weight change of Merino wethers allowed free access to lupins and either whole cottonseed or a sorghum + cottonseed meal (CSM) supplement, at frequencies ranging from 0 to 7 days/week, and to investigate the relationship between trough space per sheep $(5-50 \mathrm{~cm} /$ sheep) at the supplement self-feeders and sheep weight change when sheep were allowed access to lupins 1 day/week. Aspects of this research have been reported in conference proceedings (Bowen et al. 2007c).

\section{Materials and methods}

\section{Animals, experimental design and diets}

Three experiments were conducted at Rosebank Research Station, near Longreach, in north-west Queensland using medium to fine wool Merino wethers selected from a larger group of uniform age and origin. Experiment 1 commenced on 5 July 2006, Experiment 2 on 21 February 2007 and Experiment 3 on 30 August 2006. Prior to the experiments, the wethers grazed native Mitchell grass pasture (predominantly Astrebla spp.). Faecal egg counts were performed (ARI Wormbuster Laboratory, Yeerongpilly, Queensland) on bulk faecal samples taken per rectum from a random selection of wethers before commencement of each experiment and no worm eggs were detected. The wethers were tagged with full duplex RFID tags (Allflex, Brisbane, Queensland). During each of the experiments, the sheep were run together as one group in a pen $(28 \times 50 \mathrm{~m})$. Shade was provided by shade cloth supported by steel frames. In the group pen, sheep were provided with ad libitum access to native Flinders grass (Iseilema spp.) hay and water. In addition, a proprietary non-protein nitrogen (NPN) loose lick (113 g urea equivalent $/ \mathrm{kg}$ ) was gradually introduced by mixing with coarse salt and was provided ad libitum. Hay was provided as round bales in hay racks constructed from portable panels and the NPN loose lick was provided in troughs. Water troughs were cleaned once daily. The sheep were vaccinated against clostridial disease and scabby mouth (Glanvac 6, CSL Ltd, Parkville, Vic.).

During an initial introductory period of 5 days, all sheep in each experiment were exposed to the supplements, basal hay diet and the facilities. After the introductory period, all sheep were moved (each morning between 0800 and 0900 hours, depending on experiment) through a Prattley sheep auto-drafter (Prattley Livestock Equipment, Wagga Wagga, NSW) and drafted by RFID tag in one of three directions, depending on treatment: back into the group pen, or into one of two supplement yards, depending on treatment. The sheep passed from the supplement yards through one-way flow gates back into the group pen, in their own time. The experiments were approved by the Queensland Department of Primary Industries and Fisheries Animal Ethics Committee.

\section{Experiment 1 - lupins v. whole cottonseed}

Wethers (initially 13 months, mean \pm s.d. liveweight $49.2 \pm$ $2.18 \mathrm{~kg}, n=140$ ) were shorn $\sim 5$ months before commencement of the experiment. The wethers were stratified by liveweight and allocated at random to one of seven treatment groups in a completely randomised design, with 20 sheep per treatment. 
The treatments were: (i) no access to supplement (Control); (ii)-(iv) access to lupins 1, 2 or 7 days/week (Lup1, Lup2 and Lup7, respectively); (v)-(vii) access to whole cottonseed 1, 2 or 7 days/week (WCS1, WCS2 and WCS7, respectively). Supplement access occurred every Tuesday for treatments with a frequency of access of 1 day/week and every Monday and Thursday for treatments with a frequency of access of 2 days/week.

During the introductory period, all sheep were exposed to both lupins and whole cottonseed supplements in troughs in the group pen (at the equivalent of $50 \mathrm{~g} /$ animal.day, for both supplement types). After the introductory period, lupins were provided in supplement yard 1 (to the left of the auto-drafter) in self-feeders with $177 \mathrm{~cm}$ trough space on each of two sides. Whole cottonseed was provided in supplement yard 2 (to the right of the auto-drafter) in square-bale hay racks $(20 \times 20 \mathrm{~cm}$ mesh) with $199 \mathrm{~cm}$ trough space on each of two sides. The trough space available per sheep was kept constant $(18 \mathrm{~cm} / \mathrm{sheep}$ for lupin treatments and $20 \mathrm{~cm} / \mathrm{sheep}$ for whole cottonseed treatments) by giving access to a second supplement feeder on the days that two treatment groups had access to the supplements.

For the first 9 days of drafting during the treatment period, the sheep were held in the supplement yards until 1200 hours to allow familiarisation with the supplement. From Day 10 of drafting, the one-way flow gates on the exits from the supplement yards were opened immediately after drafting each day.

\section{Experiment 2 - lupins v. sorghum + CSM}

Wethers (initially 21 months, mean \pm s.d. liveweight $49.7 \pm$ $2.13 \mathrm{~kg}, n=140$ ) were shorn $\sim 3$ weeks before commencement of the experiment and were treated for lice (Zapp. Pour-on, Bayer Australia Ltd) off-shears. The wethers were stratified by liveweight and allocated to one of seven treatment groups in a completely randomised design with 20 sheep per treatment. The treatments were: (i) no access to supplement (Control); (ii)-(iv) access to lupins 2, 4 or 7 days/week (Lup2, Lup4 and Lup7, respectively); (v)-(vii) access to sorghum + CSM supplement 2, 4 or 7 days/week (Sorg2, Sorg4 and Sorg7, respectively). Supplement access occurred every Tuesday and Saturday for those treatment groups with a frequency of access of 2 days/week and every Monday, Wednesday, Friday and Sunday for those treatment groups with a frequency of access of 4 days/week.

The sorghum + CSM supplement consisted of $822 \mathrm{~g} / \mathrm{kg} \mathrm{DM}$ whole sorghum grain, $93 \mathrm{~g} / \mathrm{kg}$ DM cottonseed meal, $15 \mathrm{~g} / \mathrm{kg}$ DM limestone and $70 \mathrm{~g} / \mathrm{kg}$ DM coarse salt and was mixed in a cement mixer. During the introductory period, all sheep were exposed to lupins for the first 2 days of the introductory period (equivalent of $50 \mathrm{~g} /$ animal.day on Day 1 and $150 \mathrm{~g} /$ animal.day on Day 2) and were introduced to the sorghum-based supplement mix by providing the equivalent of $50,150,250,350$ and $450 \mathrm{~g}$ /animal.day over days 1-5, respectively, of the introductory period.

After the introductory period, sorghum + CSM supplement was provided in self-feeders in supplement yard 1 and lupins were provided in self-feeders in supplement yard 2. The trough space available per sheep was kept constant $(18 \mathrm{~cm} / \mathrm{sheep})$ by allowing access to a second supplement feeder on those days that two treatment groups had access to the supplements.
For the first 2 days of drafting during the treatment period, the sheep were held in the supplement yards for half an hour after drafting was completed, to allow familiarisation with the supplement. From Day 3 of drafting, the one-way flow gates on the exits from the supplement yards were opened immediately after drafting each day.

\section{Experiment 3 - trough space}

Wethers (initially 15 months, mean \pm s.d. liveweight $45.9 \pm 2.23 \mathrm{~kg}, n=192$ ) were shorn $\sim 7$ months before commencement of the experiment. The wethers' horns were trimmed and treated to prevent blowfly strike (Extinosad, Elanco Animal Health) 1 week before the experiment start. The wethers were stratified by liveweight and allocated at random to nine groups, such that each group had the same average and distribution of liveweight. The treatments were: (i) no access to supplement (Control), 30 sheep; (ii) $5.1 \mathrm{~cm}$ trough space/sheep ( $5 \mathrm{~cm}$ ), two groups of $35 \mathrm{sheep}$; (iii) $20.8 \mathrm{~cm}$ trough space/sheep $(20 \mathrm{~cm}$ ), two groups of 17 sheep; (iv) $35.4 \mathrm{~cm}$ trough space $/$ sheep $(35 \mathrm{~cm})$, two groups of 15 sheep; and (v) $50.6 \mathrm{~cm}$ trough space/sheep $(50 \mathrm{~cm})$, two groups of 14 sheep. There were two replicate groups of each of treatment groups (ii)-(v).

During the introductory period, all sheep were exposed to lupins in the group pen as for Experiment 1. After the introductory period, lupins were provided in supplement yards 1 and 2 in self-feeders (177 $\mathrm{cm}$ trough space on each of two sides). As the trough space could not be altered, the sheep numbers in each treatment group differed to achieve the desired trough space/sheep. The groups received access to supplement once/week.

For the first week of drafting during the treatment period, the sheep were held in the supplement yards until 1130 hours, to allow familiarisation with the supplement. From Week 2 of drafting, the one-way flow gates on the exits from the supplement yards were opened immediately after drafting each day.

\section{Measurements and analytical procedures}

All sheep were weighed daily (Experiments 1 and 2) or 4 days/week (Experiment 3 ) as they passed through the autodrafter. Flexi-panel readers and a data logger (Allflex, Brisbane, Qld) located at the common exit from the supplement yards recorded the time at which individual sheep returned to the group pen. In Experiment 1, due to equipment malfunction, records for time spent in the supplement yards commenced on Day 16. Sheep took $\sim 1$ week in Experiment 2 and 3 weeks in Experiment 3, to learn to find their way through the one-way flow gates without assistance. Thus, records for time spent in the supplement yards commence on Day 9 and Day 23, respectively.

In each experiment, group supplement intake was estimated for the entire feeding period and was determined as the difference between the total supplement added to the feeders and that remaining at the end of the experimental period. Subsamples were taken once per week for the hay (Experiment 2 only) and NPN loose lick and every time supplement was weighed in or out of the self-feeders for the lupins, whole cottonseed and sorghum + CSM supplement. Subsamples were stored at air temperature and were later bulked to provide one representative sample for chemical analysis for each feed. For Experiments 1 and 3 (which were consecutive in time), 
subsamples were taken from all available hay bales by a corer to form the one representative bulk sample for analysis. The DM content of feeds was determined on additional duplicate subsamples by drying at $80^{\circ} \mathrm{C}$ until constant weight.

Feed samples were milled to $<1 \mathrm{~mm}$ before chemical analyses, which were on a DM basis. The ash content was determined by heating dry samples in an electric muffle furnace (Thermogravimetric analyser TGA-601, LECO Corporation, St Joseph, MI) at $610^{\circ} \mathrm{C}$ to constant weight under an atmosphere of oxygen. Feed samples were analysed for total $\mathrm{N}$ content by a combustion method (Sweeney 1989) using an Elementar RapidN analyser (Elementar analysensysteme $\mathrm{GmbH}$, Germany). Ash-free neutral detergent fibre (NDF) and ash-free acid detergent fibre (ADF) contents were determined using the Fibretec 2021 Fibrecap system developed by Foss Tecator (Foss Tecator 2002a, 2002b). Crude fibre (CF) was determined by the method of the AOAC (1975) adapted for the Fibretec 2021 Fibrecap System by Foss Tecator (Foss Tecator 2002c). Ether extract (EE), or crude fat, content was determined by soxhlet extraction using petroleum ether (boiling range $40-60^{\circ} \mathrm{C}$ ) for $16 \mathrm{~h}$ (Kent-Jones and Amos 1957).

\section{Calculations}

For each experiment, the metabolisable energy (ME) content of Flinders grass hay was predicted using Eqn 67 from MAFF (1975) with a correction for ash content:

$$
\begin{gathered}
\text { ME density }=13.5-(0.015 \mathrm{ADF}+0.015 \mathrm{ash})+ \\
0.014 \text { crude protein }(\mathrm{CP})
\end{gathered}
$$

The ME content of supplements was predicted using Eqn 75 from MAFF (1975):

ME density $=0.012 \mathrm{CP}+0.031 \mathrm{EE}+0.005 \mathrm{CF}+0.014 \mathrm{NFE}$

where NFE (nitrogen-free extract $)=1000-(\mathrm{CP}+\mathrm{EE}+\mathrm{CF}+\mathrm{ash})$.

For both equations, ME density is expressed as $\mathrm{MJ} / \mathrm{kg} \mathrm{DM}$ and all other concentrations are in $\mathrm{g} / \mathrm{kg} \mathrm{DM}$.

\section{Statistical analyses}

The statistical package, Genstat for Windows, 9th edition (Payne et al. 2006), was used for all statistical analyses. In Experiment 1 (lupins $v$. whole cottonseed), linear growth rates of individual sheep were analysed as a completely randomised design, taking into account that the variance of the group with access to lupins 7 days/week was much larger than the variances of the other groups, which were homogeneous (according to Bartlett's test for homogeneity of variances (Snedecor and Cochran 1980). Pair-wise differences between means were tested using a protected least significance difference procedure $(P=0.05)$. Also, regression analyses of mean liveweights of the treatment groups on time were undertaken with the reciprocals of the variance as weights. Average time spent in the supplement yards was analysed by analysis of variance after using logarithms to stabilise the variance. Linear growth rates of individual sheep within each of the treatment groups were regressed against the mean time spent in the supplement yards. Similar analyses were undertaken on the data from Experiment 2 (lupins v. sorghum + CSM). However, the variances for weights and weight change of the groups were homogeneous and it was not necessary to transform the average time spent in the supplement yards to stabilise the variance.

In Experiment 3 (trough space) linear growth rates of individual sheep and time spent in the supplement yards were analysed as a completely randomised design, with the group of sheep as the experimental unit. Regression lines were also fitted to the average liveweight of the treatment groups over time, with the number of sheep in the treatment group as weights. Treatment group averages of rate of liveweight change were regressed against trough space allocation and corresponding averages of time spent in the supplement yards, with the number of sheep in the treatment groups as weights. The averages of time spent in the supplement yards were also regressed against trough space, with the number of sheep in the treatment group as weights.

To increase the generality of the conclusions from the experiments with regard to response to supplements, 'experiment' was considered as a random factor and data for liveweight change and time spent in the supplement yard, for the three experiments, were combined and analysed. For Experiment 3, only the Control group and the supplemented groups which had equivalent trough space to Experiments 1 and 2 were used in the combined analysis. The analyses were weighted with the number of animals in each draft. As the whole cottonseed and sorghum + CSM treatments were each present in only one experiment, these means were less well estimated than other means and this is reflected in their standard errors. Mean growth rates of all groups from Experiments 1 and 2 were regressed against frequency of access for each supplement type. Mean time spent in the supplement yards (back-transformed values of the mean logarithm for Experiment 1) were also regressed against frequency of access for each supplement type.

\section{Results}

\section{Experiment 1 - lupins v. whole cottonseed}

The chemical composition of hay and supplements offered during the experiment is given in Table 1. If it is assumed that all sheep from all treatment groups consumed equal quantities of supplement at each time of access, the average consumption of lupins and whole cottonseed was 895 and $228 \mathrm{~g}$ DM/animal.access, respectively.

The weighted regression analysis of mean liveweight $(\mathrm{kg})$ on time (day) gave the same conclusions as the analysis of variance of the linear growth rates of individual sheep (Table 2), with the slopes of the lines giving approximately the same values as the means in Table 2:

(i) Control, $y=48.5$ (s.e. 0.17) -0.0524 (s.e. 0.00633$) x$;

(ii) Lup1, $y=48.9$ (s.e. 0.19 ) -0.0297 (s.e. 0.00754$) x$;

(iii) Lup2, $y=48.9$ (s.e. 0.20$)+0.0076$ (s.e. 0.00763$) x$;

(iv) Lup7, $y=49.0$ (s.e. 0.25 ) +0.123 (s.e. 0.0105$) x$;

(v) WCS1, $y=48.7$ (s.e. 0.17 ) -0.0596 (s.e. 0.00674$) x$;

(vi) WCS2, $y=48.7$ (s.e. 0.20 ) -0.0383 (s.e. 0.00755 ) $x$;

(vii) WCS7, $y=49.5$ (s.e. 0.21 ) -0.0443 (s.e. 0.00803 ) $x$; (adjusted $r^{2}=78.7, P<0.001$ ).

During the 44-day measurement period, sheep allowed access to lupins 7 days/week gained weight, while sheep in the Control, Lup1, WCS1, WCS2 and WCS7 groups lost weight. Sheep allowed access to lupins 2 days/week maintained weight 
(liveweight change over time was not significantly different from 0 ). Bartlett's test for homogeneity of variances for growth rate showed that the variation between all groups was significantly different (Chi-square $=23.37$ for 6 d.f., $P<0.001$ ) unless the Lup7 group was excluded (Chi-square $=6.67$ for 5 d.f., $P=0.247)$. Sheep growth rate increased $(P<0.05)$ as frequency of access to lupins was increased from 0 to 7 days/week. However, the growth rates of sheep allowed access to whole cottonseed 1, 2 or 7 days/week were not significantly different from that of the Control group.

As frequency of access to lupins was increased from 1 to 7 days/week, the time spent by sheep in the supplement yards decreased $(P<0.05)$ (Table 2$)$. A similar trend was not evident for the whole cottonseed treatments. In general, sheep receiving access to whole cottonseed spent less time in the supplement yards than sheep receiving access to lupins. When linear growth rates of individual sheep were regressed against the average time spent in the supplement yards, within each treatment group, the slopes of the relationships were not significantly different $(P>0.05)$ from 0 , or each other.

Experiment 2 - lupins v. sorghum + CSM

Table 1 shows the chemical composition of hay and supplements offered during the experiment. If it is assumed that all sheep from all treatment groups consumed equal quantities of supplement at each time of access, the average consumption of lupins and sorghum + CSM supplement was 849 and $884 \mathrm{~g}$ DM/animal.access, respectively.

The weighted regression analysis of mean liveweight $(\mathrm{kg})$ on time (day) gave the same conclusions as the analysis of variance of the linear growth rates of individual sheep (Table 2) with the slopes of the lines giving approximately the same values as the means in Table 2:

(i) Control, $y=49.4$ (s.e. 0.16) +0.0195 (s.e. 0.00486) $x$;

(ii) Lup2, $y=49.3$ (s.e. 0.19$)+0.0310$ (s.e. 0.00560$) x$;

(iii) Lup4, $y=49.0$ (s.e. 0.21$)+0.0985$ (s.e. 0.00650$) x$; (iv) Lup7, $y=47.9$ (s.e. 0.21$)+0.1543$ (s.e. 0.00678$) x$;

(v) Sorg2, $y=49.2$ (s.e. 0.17$)+0.0238$ (s.e. 0.00557) $x$;

(vi) Sorg4, $y=49.3$ (s.e. 0.19) +0.0637 (s.e. 0.00606) $x$;

(vii) Sorg7, $y=48.5$ (s.e. 0.16) +0.0879 (s.e. 0.00509)x; (adjusted $\left.r^{2}=80.6, P<0.001\right)$.

During the 57-day measurement period all groups, including the Control animals, gained weight (i.e. liveweight change over time was significantly different from 0 ). Sheep allowed access to lupins 7 days/week had significantly greater liveweight gain than all other treatment groups. Access to either lupins or sorghum + CSM supplement 2 days/week did not significantly increase growth rate compared with the Control group. Within each supplement type, increasing frequency of access to supplement led to increased growth rate $(P<0.05)$.

As frequency of access to lupins was increased from 2 to 7 days/week, the time spent by sheep in the supplement yards decreased $(P<0.05)$ (Table 2$)$. A similar trend was not evident for the sorghum + CSM supplement. When linear growth rates of individual sheep were regressed against the average time spent in the supplement yards, for each treatment group, growth rates of sheep in Sorg4 and Sorg7 groups significantly increased ( $P=0.009$ and $P=0.015$, respectively) with average time spent in the supplement yard, while the slopes for the other treatment groups were not significantly different from $0(P>0.05)$.

\section{Experiment 3 - trough space}

The chemical composition of hay and supplements offered during the experiment is given in Table 1. If it is assumed that all sheep from all treatment groups consumed equal quantities of supplement at each time of access, the average consumption of lupins was $650 \mathrm{~g} \mathrm{DM} /$ animal.access.

With the exception of the $5 \mathrm{~cm}$ treatment group, the slopes of the regressions of mean liveweight over time were not significantly different from 0 . However, as the slopes for the five treatment groups were not significantly different to one another, parallel lines could be used to describe the common

Table 1. Dry matter content (DM, g/kg, as fed), estimated metabolisable energy concentration (ME, MJ/kg DM) and concentrations $(\mathrm{g} / \mathrm{kg} \mathrm{DM})$ of crude protein $(\mathrm{CP}, \mathrm{N} \times 6.25)$, organic matter $(\mathrm{OM})$, neutral detergent fibre (NDF), acid detergent fibre (ADF), crude fibre (CF) and ether extract (EE) in hay and supplements offered to Merino wethers in Experiments 1-3

\begin{tabular}{|c|c|c|c|c|c|c|c|c|}
\hline & $\mathrm{DM}$ & ME & $\mathrm{CP}$ & $\mathrm{OM}$ & NDF & $\mathrm{ADF}$ & $\mathrm{CF}$ & $\mathrm{EE}$ \\
\hline \multicolumn{9}{|c|}{ Experiment 1} \\
\hline Flinders grass hay & 868 & 5.9 & 41.3 & 865 & 658 & 412 & - & - \\
\hline Lupins & 932 & 12.4 & 309 & 973 & - & - & 188 & 62 \\
\hline Whole cottonseed & 901 & 13.6 & 219 & 961 & - & - & 310 & 197 \\
\hline NPN loose lick & 952 & - & 408 & - & - & - & - & - \\
\hline \multicolumn{9}{|c|}{ Experiment 2} \\
\hline Flinders grass hay & 913 & 6.6 & 48.1 & 895 & 586 & 402 & - & - \\
\hline Lupins & 934 & 12.8 & 324 & 971 & - & - & 126 & 58 \\
\hline Sorghum + cottonseed meal supplement & 911 & 12.3 & 142 & 865 & - & - & 13 & 33 \\
\hline Sorghum grain & 905 & 14.0 & 118 & 984 & - & - & 12 & 36 \\
\hline Cottonseed meal & 930 & 11.8 & 506 & 924 & - & - & 73 & 32 \\
\hline NPN loose lick & 953 & - & 440 & - & - & - & - & - \\
\hline \multicolumn{9}{|c|}{ Experiment 3} \\
\hline Flinders grass hay & 947 & 5.9 & 41.3 & 865 & 658 & 412 & - & - \\
\hline Lupins & 945 & 12.4 & 326 & 970 & - & - & 167 & 55 \\
\hline NPN loose lick & 973 & - & 371 & - & - & - & - & - \\
\hline
\end{tabular}


slope ( -8 g/animal.day), which was significantly different from 0 . There were no significant differences among any of the treatment groups for rate of liveweight change when linear regressions were fitted to sheep weights over time for individual animals (Table 2). In addition, there were no significant differences between the treatment groups for the average time spent in the supplement yards (Table 2). The variation between animals in rate of liveweight change (mean square $=862$ ) was greater than the variation between replicated groups (mean square $=423)$ although this was not the case for the time spent in the supplement yards $(0.0291 v .0 .0551)$.

No relationship was found between growth rate of the treatment groups and trough space allocation per sheep $(P=0.38)$. For those treatment groups with access to supplement, liveweight change was not significantly related to time spent in the supplement yard $(P=0.59)$ which, in turn, was not related to trough space allocation $(P=0.33)$.

\section{Combined analysis}

The results from the combined analysis of mean growth rate and time spent in supplement yards are given in Table 3, with mean

Table 2. Mean growth rate and time spent in supplement yards for Merino wethers in Experiments 1-3

Standard error of difference (s.e.d.) is presented. Treatment descriptions are given in the text. For each experiment, values within columns followed by different lowercase letters are significantly different at $P=0.05$. Data for time in supplements yards for Experiment 1 were log-transformed before analysis (means in parentheses); back-transformed means are also shown

\begin{tabular}{|c|c|c|}
\hline & $\begin{array}{l}\text { Growth rate } \\
\text { (g/animal.day) }\end{array}$ & $\begin{array}{l}\text { Time in supplement yards } \\
\text { (h/feeding session) }\end{array}$ \\
\hline \multicolumn{3}{|c|}{ Experiment 1} \\
\hline Control & $-54 \mathrm{a}$ & - \\
\hline Lup1 & $-30 b$ & $0.92(-0.09 a)$ \\
\hline Lup2 & $11 \mathrm{c}$ & $0.76(-0.27 b)$ \\
\hline Lup7 & $127 d$ & $0.50(-0.70 \mathrm{c})$ \\
\hline WCS1 & $-61 \mathrm{a}$ & $0.38(-0.96 \mathrm{~d})$ \\
\hline WCS2 & $-39 a b$ & $0.49(-0.72 c)$ \\
\hline WCS7 & $-43 \mathrm{ab}$ & $0.35(-1.04 \mathrm{~d})$ \\
\hline s.e.d. & $11.9^{\mathrm{A}}, 17.8^{\mathrm{B}}$ & $(0.089)$ \\
\hline \multicolumn{3}{|c|}{ Experiment 2} \\
\hline Control & $19 \mathrm{a}$ & - \\
\hline Lup2 & $35 \mathrm{a}$ & $0.92 \mathrm{a}$ \\
\hline Lup4 & $103 \mathrm{c}$ & $0.74 \mathrm{~b}$ \\
\hline Lup7 & $155 \mathrm{~d}$ & $0.54 \mathrm{c}$ \\
\hline Sorg2 & $28 \mathrm{a}$ & $0.61 \mathrm{cb}$ \\
\hline Sorg4 & $71 \mathrm{~b}$ & $0.63 \mathrm{cb}$ \\
\hline Sorg7 & $98 \mathrm{c}$ & $0.59 \mathrm{c}$ \\
\hline s.e.d. & 11.6 & 0.068 \\
\hline \multicolumn{3}{|c|}{ Experiment 3} \\
\hline Control & -4 & - \\
\hline $5 \mathrm{~cm}$ & -12 & 0.48 \\
\hline $20 \mathrm{~cm}$ & -10 & 0.47 \\
\hline $35 \mathrm{~cm}$ & -9 & 0.62 \\
\hline $50 \mathrm{~cm}$ & -2 & 0.54 \\
\hline Overall mean & -8 & 0.52 \\
\hline Average s.e.d. & 5.0 & 0.056 \\
\hline
\end{tabular}

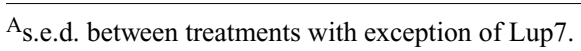

${ }^{B}$ s.e.d. between Lup7 and any of the other treatment groups. values corrected for the effect of experiment. The results from this analysis confirm the trends reported for the individual experiments. Linear relationships showing growth rate responses to frequency of access to supplement are shown in Fig. 1. These data show that sheep growth rate response to frequency of access to lupins was significantly different $(P<0.05)$ from that for whole cottonseed and sorghum + CSM. Sheep growth rate response for whole cottonseed was not significantly different from 0 . The linear relationships showed that for each additional day of access, liveweight change was increased by 26, 21 and $12 \mathrm{~g}$ /day for lupins (Experiment 1), lupins (Experiment 2) and sorghum + CSM (Experiment 2), respectively. The slopes of the growth rate response for lupins were not significantly different for Experiments 1 and 2, with the mean response being $23 \mathrm{~g} /$ day.

Linear relationships between the mean time spent in the supplement yards and frequency of access to supplement are shown in Fig. 2. The response to lupins was the same in both Experiments 1 and 2, but significantly different $(P<0.05)$ from that for whole cottonseed and sorghum + CSM which, in turn, were not significantly different from 0 .

\section{Discussion}

The very similar growth rate response of Merino wethers to increased frequency of access to lupins in Experiments 1 and 2 was observed, despite an age difference of the wethers of $\sim 8$ months and despite a large difference between experiments in the growth rate of the Control sheep. A similar quantity of lupins was consumed per animal per access in the two experiments and would have been a major contributor to the consistent liveweight responses.

Despite similar consumption of the sorghum + CSM supplement and lupins in Experiment 2 (884 v. $849 \mathrm{~g}$ $\mathrm{DM} /$ animal.access, respectively), a poorer growth response was observed for sheep allowed access to the sorghum + CSM supplement. This may be related to the lower CP content of the

Table 3. Mean growth rate and time spent in supplement yards for Merino wethers from combined analysis of Experiments 1-3

Average standard error of difference (s.e.d.) is presented. Treatment descriptions are given in the text. Values within columns followed by different lowercase letters are significantly different at $P=0.05$ for growth rate, and $P=0.053$ for time in supplement yards when the degrees of freedom for error was only 2

\begin{tabular}{lcc}
\hline & $\begin{array}{c}\text { Growth rate } \\
(\mathrm{g} / \text { animal.day })\end{array}$ & $\begin{array}{c}\text { Time in supplement yards } \\
(\mathrm{h} / \text { feeding session) }\end{array}$ \\
\hline Control & $-13 \mathrm{a}$ & - \\
Lup1 & $-12 \mathrm{ab}$ & $0.80 \mathrm{a}$ \\
Lup2 & $26 \mathrm{bc}$ & $0.68 \mathrm{ab}$ \\
Lup4 & $86 \mathrm{~d}$ & $0.52 \mathrm{abc}$ \\
Lup7 & $144 \mathrm{e}$ & $0.35 \mathrm{~cd}$ \\
Sorg2 & $10 \mathrm{abc}$ & $0.40 \mathrm{~cd}$ \\
Sorg4 & $54 \mathrm{~cd}$ & $0.42 \mathrm{bd}$ \\
Sorg7 & $81 \mathrm{~d}$ & $0.38 \mathrm{~cd}$ \\
WCS1 & $-38 \mathrm{a}$ & $0.27 \mathrm{~cd}$ \\
WCS2 & $-17 \mathrm{ab}$ & $0.37 \mathrm{~cd}$ \\
WCS7 & $-21 \mathrm{ab}$ & $0.24 \mathrm{~cd}$ \\
Average s.e.d. & 19.7 & 0.068 \\
\hline
\end{tabular}


sorghum + CSM supplement, with the additional CP supplied per access to the sorghum + CSM supplement being less than half that supplied as a result of access to lupins $(126 v .275 \mathrm{~g}$ $\mathrm{CP}$ ). Compounding the lower total CP supply, the proportion of protein that is degradable in the rumen is lower for sorghum and cottonseed meal relative to lupins (SCA 1990; AFRC 1993).

Another possible factor leading to the lower performance of sheep given access to the sorghum + CSM supplement is the possibility of a greater reduction of rumen fibre digestion due to sorghum cereal starch, compared with lupin carbohydrates. Additionally, sorghum grain is known to have a low digestibility of starch when fed to cattle (Rooney and Pflugfelder 1986). Consistent with this, high levels of faecal starch have been measured for sheep fed whole or cracked sorghum grain (Bowen et al. 2007a, 2007b). Thus, although the additional supply of ME from supplement was calculated to be similar for sorghum + CSM and lupins (10.9 MJ ME/animal.access for both), it is possible that less energy was actually available from the sorghum + CSM supplement.

The inclusion of salt in the sorghum + CSM supplement at $70 \mathrm{~g} / \mathrm{kg}$ DM appeared successful in preventing excess intakes and any associated clinical acidosis problems that may otherwise have resulted from providing free access to the highgrain supplement. While the time spent by sheep in the lupin supplement yards increased as access was provided less

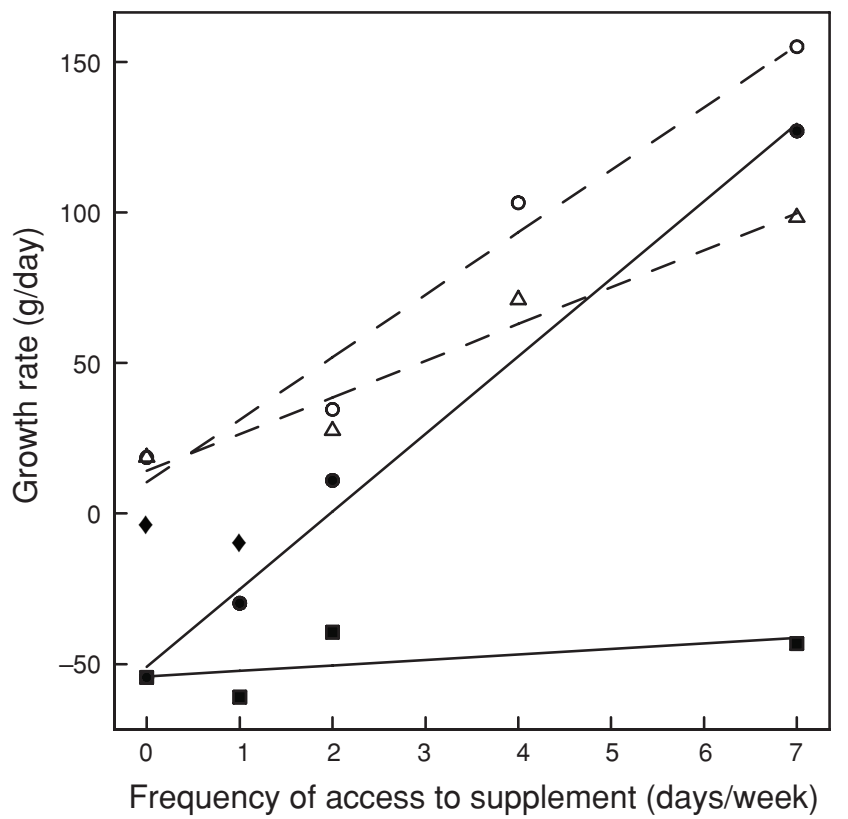

Fig. 1. Mean growth rate responses to frequency of access to supplement. Experiment 1: access to lupin grain $(\bullet)$, access to whole cottonseed (ם). Experiment 2: access to lupin grain $(\bigcirc)$, access to sorghum + cottonseed meal $(\mathrm{CSM})$ supplement $(\triangle)$. Experiment 3: access to lupin grain $(\diamond)$. Experiment 1 equations are: lupins, $y=-51.0$ (s.e. 7.72$)+25.8$ (s.e. 2.10$) x$; whole cottonseed, $y=-54.1$ (s.e. 7.72) +1.8 (s.e. 2.10) $x$; Experiment 2 equations are: lupins, $y=10.4$ (s.e. 9.08) +20.8 (s.e. 2.19) $x$; sorghum + CSM, $y=14.2$ (s.e. 9.08$)+12.2($ s.e. 2.19$) x$; $\left(\right.$ adjusted $r^{2}=97.4$, $P<0.001)$. The slope of line for whole cottonseed is not significantly different from 0 ; the slopes of lines for lupins are not significantly different for Experiments 1 and 2, common slope 23.4 (s.e. 1.51). frequently, the time spent by sheep given access to the sorghum + CSM supplement remained constant. The reason for this may have been due to the need for these sheep to leave the feeding area to seek water more quickly than for sheep consuming lupins, limiting them to an average of $\sim 0.60 \mathrm{~h} /$ feeding session.

In Experiment 1, access to whole cottonseed resulted in no detectable difference in growth rate compared with the Control group, even when sheep were allowed access 7 days/week. The poor response to the whole cottonseed supplement may be partly related to the low levels of cottonseed intake in this system: $228 v .895 \mathrm{~g} \mathrm{DM} /$ animal.access for lupins. These levels of supplement intake equate to $3.1 \mathrm{MJ} \mathrm{ME}$ and $49.9 \mathrm{~g} \mathrm{CP}$ per access for whole cottonseed and 11.1 MJ ME and $277 \mathrm{~g} \mathrm{CP}$ per access for lupins. The residual cotton fibres on the seed could have absorbed saliva or ruminal fluid, making it necessary for the animals to leave the feeding area to seek water more quickly than was the case for lupins. Sheep in Experiment 1 with access to cottonseed generally remained in the feeding area for shorter periods than those offered lupins (Table 2). It is also possible that the relatively high oil content of the cottonseed $(20 \%)$ may have depressed intake of both cottonseed and hay, because of a reduction in the numbers of cellulolytic rumen microorganisms or inhibition of their activity (Devendra and Lewis 1974).

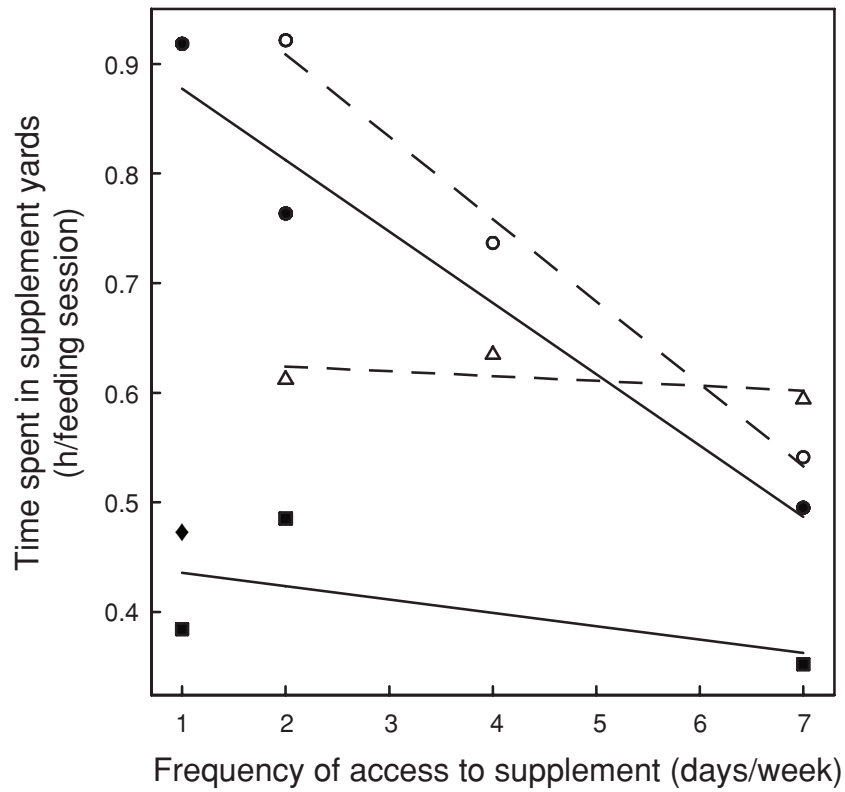

Fig. 2. Relationship between the mean time spent by sheep in the supplement yards and frequency of access to supplement. Experiment 1: access to lupin grain (), access to whole cottonseed (ם). Experiment 2: access to lupin grain $(\bigcirc)$, access to sorghum + cottonseed meal (CSM) supplement $(\triangle)$. Experiment 3: access to lupin grain $(\diamond)$. Experiment 1 equations are: lupins, $y=0.94$ (s.e. 0.051 ) -0.065 (s.e. 0.0120$) x$; whole cottonseed, $y=0.45$ (s.e. 0.051 ) -0.012 (s.e. 0.012) $x$; Experiment 2 equations are: lupins, $y=1.06$ (s.e. 0.074 ) -0.075 (s.e. 0.015) $x$; sorghum + CSM, $y=0.63$ (s.e. 0.074) -0.004 (s.e. 0.0150) $x$; (adjusted $\left.r^{2}=91.4, P=0.007\right)$. The slopes of lines for whole cottonseed and sorghum + CSM are not significantly different from 0 ; the slopes of lines for lupins are not significantly different for Experiments 1 and 2, common slope -0.066 (s.e. 0.010 ). 
Whole cottonseed is widely used as a protein and energy supplement for ruminants in northern Australia because of its favourable price and regional availability. Industry experience and previous experiments indicate that the voluntary intake of whole cottonseed supplement for sheep consuming low quality roughage can be variable and low, except in drought conditions when low levels of roughage are available (Bird and Dicko 1987; Department of Primary Industries and Fisheries 2006). Similar reports of low and variable intake of whole cottonseed supplement exist for cattle (Dixon et al. 1998; Wood et al. 2000). The lower intake of whole cottonseed compared with lupins in Experiment 1 is consistent with these reports.

Although the time spent by sheep in the lupin supplement yards decreased as access was provided more frequently in Experiments 1 and 2 (Fig. 2), this did not result in a non-linear liveweight response to increased frequency of access (Fig. 1). It was not possible to measure individual animal supplement intake in these experiments and thus we cannot determine whether the time spent by sheep in the supplement yards was correlated with intake. In Experiments 1 and 2, when individuals within treatment groups were examined, there was a lack of any correlation between liveweight change and time spent in the supplement yards for all treatment groups, except those given access to the sorghum + CSM supplement 4 and 7 days/week.

Dixon and Hosking (1992) reported a range in supplement conversion efficiency for sheep of $0.2-0.8 \mathrm{~g}$ liveweight change/g grain legume DM, with the level of response to grain legume supplement inversely related to the growth rate of unsupplemented animals and, hence, to the quality of their basal roughage diets. The estimated efficiency of supplement conversion in our experiments was at the lower end of this range for sheep offered supplement 7 days/week, being at 0.20, 0.16 and $0.09 \mathrm{~g}$ liveweight change/g supplement DM, for sheep offered lupins in Experiment 1, lupins in Experiment 2 and sorghum + CSM supplement, respectively.

In Experiment 3, there was no relationship between trough space allocation per sheep and rate of liveweight change over the range of 5-50 cm trough space per sheep, although there was also no liveweight response, compared with the Control group, to providing lupins 1 day/week in this experiment. However, the lack of a significant relationship between the time spent by sheep in the lupin supplement yards and either liveweight change or trough space allocation provides further evidence that trough space allocation is not a limiting factor in this system.

The range of trough space allocation studied in our experiment covered the industry recommendations for feedlotting conditions of $10 \mathrm{~cm}$ trough space/sheep for selffeeders and $15 \mathrm{~cm}$ trough space/sheep when open troughs are used (Bell et al. 2002; Davis 2003). However, it is likely that guidelines developed for feedlotting conditions may not be relevant to the remote drafting supplementation system where sheep receive infrequent access to supplement in a grazing system. Bowman and Sowell (1997) concluded that either excessive or restricted trough space can cause increased dominance behaviours and, thus, increased between-animal variation in supplement consumption. Such an effect was not apparent in sheep weight change data over the range of trough space allocation studied in our experiment.
In conclusion, these experiments have provided predictive relationships for liveweight change with different frequencies of access to three types of supplement in a remote drafting system. Although our data are limited by the number of points, these relationships provide a starting point with which to determine the frequency of access to supplement required to achieve animal weight targets. Additionally, our data showed that restricting self-feeder trough space down to $5 \mathrm{~cm} / \mathrm{sheep}$, in a remote drafting system, did not negatively affect sheep liveweight change. This will allow the costs of providing selffeeders to be kept to a minimum. Combined, these results provide proof of concept for the new supplementation system. However, it is probable that, under grazing conditions, sheep behaviour and supplement intake may differ from patterns observed in the more controlled conditions of our pen experiments with factors, such as substitution rates, further interacting with frequency of access to supplement in affecting intake, grain conversion efficiency and growth response. Further research to refine and extend understanding of the system in the field is warranted.

\section{Acknowledgements}

These experiments were funded by the Australian Sheep Industry Cooperative Research Centre with in-kind contributions from the Department of Primary Industries and Fisheries, Queensland (DPI\&F). We are grateful to Peter Martin, Adam Pytko and Madeleine Modina of the Health and Nutritional Biochemistry Laboratory of DPI\&F for conducting laboratory analyses.

\section{References}

AFRC (1993) 'Energy and protein requirements of ruminants. An advisory manual prepared by the AFRC Technical Committee on the responses to nutrients.' (CAB International: Wallingford, UK)

AOAC (1975) 'Official methods of analysis.' (Association of Official Analytical Chemists: Washington, DC)

Beaty JL, Cochran RC, Lintzenich BA, Vanzant ES, Morrill JL, Brandt RT Jr, Johnson DE (1994) Effect of frequency of supplementation and protein concentration in supplements on performance and digestion characteristics of beef cattle consuming lowquality forages. Journal of Animal Science 72, 2475-2486.

Beeson WM, Perry TW, Mohler M (1957) Self-feeding free choice vs. selffeeding a complete mixture for fattening steers. Journal of Animal Science 16, 787-795.

Bell AK, Shands CG, Hegarty RS (2002) 'Grain finishing of lambs.' (Meat and Livestock Australia: North Sydney, NSW)

Bird SH, Dicko M (1987) Cottonseed supplements for sheep. Recent Advances in Animal Nutrition in Australia 9, 80-88.

Bohnert DW, Schauer CS, DelCurto T (2002) Influence of rumen protein degradability and supplementation frequency on performance and nitrogen use in ruminants consuming low-quality forage: cow performance and efficiency of nitrogen use in wethers. Journal of Animal Science 80, 1629-1637.

Bowen MK, Pepper PM, Patterson E, McConnel I, Jordan D (2007a) Growth and carcass characteristics of cast-for-age Merino ewes fed sorghum-based feedlot diets. Australian Journal of Experimental Agriculture 47, 1309-1316. doi:10.1071/EA06145

Bowen MK, Pepper PM, Winkleman J, McConnel I (2007b) Concentrates based on sorghum grain provide a basis for a finishing system for crossbred lambs. Australian Journal of Experimental Agriculture 47, 1317-1325. doi:10.1071/EA06189

Bowen MK, Pepper PM, Winkleman JL, Rowe JB (2007c) Automated feeding systems for grazing sheep: how does frequency of access affect 
rate of weight change? Recent Advances in Animal Nutrition in Australia 16, 229-234

Bowman JGP, Sowell BF (1997) Delivery method and supplement consumption by grazing ruminants: a review. Journal of Animal Science 75, 543-550.

Davis J (2003) 'Feedlotting lambs. A producer's guide.' (Department of Primary Industries: Rutherglen, Vic.)

Department of Primary Industries and Fisheries (2006) Livestock nutrition, supplementary feeding of sheep using cottonseed, DPI\&F Note. (Department of Primary Industries and Fisheries: Brisbane, Qld) Available at http://www2.dpi.qld.gov.au/sheep/8091.html [Verified 17 June 2008]

Devendra C, Lewis D (1974) The interaction between dietary lipids and fibre in the sheep. 2. Digestibility studies. Animal Production 48, 67-76.

Dixon RM, Hosking BJ (1992) Nutritional value of grain legumes for ruminants. Nutrition Research Reviews 5, 19-43. doi:10.1079/ NRR19920005

Dixon RM, Smith DR, Lindsay JA (1998) Whole white cottonseed or cottonseed meal as supplements for young steers fed low quality roughage. Animal Production in Australia 22, 338.

Easton EG, Hocking Edwards JE, White CL (1998) The effect of adding salt to a canola meal supplement on wool growth in weaner sheep. Animal Production in Australia 22, 257-260.

Egan AR, Frederick F, Dixon RM (1987) Improving efficiency of use of supplements by manipulation of management procedures. In 'Ruminant feeding systems using fibrous agricultural residues. Proceedings of the 6th annual workshop of the Australian-Asian Fibrous Agricultural Residues Research Network, Los Baños, Philippines'. (Ed. RM Dixon) pp. 69-81. (Australian-Asian Fibrous Agricultural Residues Research Network: Los Baños, Philippines)

Farmer CG, Cochran RC, Simms DD, Klevesahl EA, Wickersham TA, Johnson DE (2001) The effects of several supplementation frequencies on forage use and the performance of beef cattle consuming dormant tallgrass prairie forage. Journal of Animal Science 79, 2276-2285.

Foss Tecator (2002a) 'Application sub-note ASN 3805. The determination of neutral detergent fibre using the Fibercap system.' (Foss Tecator: Hoganas, Sweden)

Foss Tecator (2002b) 'Application sub-note ASN 3804. The determination of acid detergent fibre using the Fibercap system.' (Foss Tecator: Hoganas, Sweden)

Foss Tecator (2002c) 'Application sub-note ASN 3801. The determination of crude fibre in feed according to AOAC, ISO, AACC and AOCS standards using the Fibercap system.' (Foss Tecator: Hoganas, Sweden)

Godfrey SI, Rowe JB, Speijers EJ, Toon W (1993) Lupins, barley or barley plus virginiamycin as supplements for sheep at different feeding intervals. Australian Journal of Experimental Agriculture 33, 135-140. doi:10.1071/EA9930135

Hawthorne WA, Stacey RW (1984) The influence of the quantity and frequency of feeding a lupin grain supplement to grazing lambs. Animal Production in Australia 15, 691.
Jolly S, Wallace A (2006) 'Best practice for production feeding of lambs: a review of the literature.' (Meat and Livestock Australia: North Sydney, NSW)

Jordan DJ, Hatcher S, Lee GJ, McConnel I, Bowen MK, Della Bosca AJ, Rowe JB (2006) Nutritional management of reproductive efficiency. International Journal of Sheep and Wool Science 54, 35-41.

Kent-Jones DW, Amos AJ (1957) 'Modern cereal chemistry.' 5th edn. (Northern Publishing Co. Ltd: Liverpool, UK)

MAFF (1975) Energy allowances and feeding systems for ruminants. Technical Bulletin 33. Ministry of Agriculture, Fisheries and Food, London.

Payne RW, Harding SA, Murray DA, Soutar DM, Baird DB, et al. (2006) 'The guide to GenStat release 9. Part 2: statistics.' (VSN International Ltd: Hemel Hempstead, UK)

Riggs JK, Colby RW, Sells LV (1953) The effect of self-feeding saltcottonseed meal mixtures to beef cows. Journal of Animal Science 12, 379-393.

Rooney LW, Pflugfelder RL (1986) Factors affecting starch digestibility with special emphasis on sorghum and corn. Journal of Animal Science 63, 1607-1623.

Rowe JB (2004) Potential benefits of precision nutrition to increase reproductive efficiency under grazing conditions. Animal Production in Australia 25, 144-147.

Rowe JB, Atkins KD (2006) Precision sheep production - pipedream or reality? Animal Production in Australia 26, Short Communication number 33.

Rowe JB, Masters DG (2005) Precision nutrition for Merino ewes. Recent Advances in Animal Nutrition in Australia 15, 221-228.

SCA (1990) 'Feeding standards for Australian livestock: ruminants.' (CSIRO Publishing: Melbourne)

Schauer CS, Lardy GP, Slanger WD, Bauer ML, Sedivec KK (2004) Self-limiting supplements fed to cattle grazing native mixed-grass prairie in the northern Great Plains. Journal of Animal Science 82, 298-306.

Simeone A, Beretta V, Rowe JB, Baldi F (2003) Supplementing grazing beef cattle weekly or daily with whole maize grain. Recent Advances in Animal Nutrition in Australia 14, 14A.

Snedecor GW, Cochran WG (1980) 'Statistical methods.' 7th edn. (Iowa State University Press: Ames, IA)

Sweeney RA (1989) Generic combustion method for determination of crude protein in feeds. Journal - Association of Official Analytical Chemists 72, 770-774.

Wood AG, Bolam MJ, Krebs GL, Andressen AR (2000) Whole cottonseed as a supplement for weaner cattle offered Pangola grass hay. Animal Production in Australia 23, 409-412.

Manuscript received 17 December 2007, accepted 18 May 2008 